\title{
Course Teaching Reform Research of English Academic Paper Writing for English Majors Based on Blended Learning
}

\author{
Xian Tang ${ }^{1, *}$
}

\author{
${ }^{1}$ Wuhan Textile University, Wuhan, China \\ *Email: txianne@163.com
}

\begin{abstract}
In the context of the teaching reform of English majors, it is important to make some adjustments to the traditional course teaching. This paper summarizes the present problems in the teaching of the course--English academic paper writing and then points out the importance of the application of blended learning in this course. Combining the needs of the course, it introduces the online platform, the way to keep balance between online and offline learning and the formative assessment of blended learning. Finally, it introduces the result of students' survey findings of their learning experience. The conclusions are as follows: Blended learning can solve the problem of limited class learning time with a difficult course. The teacher should keep a balance between online learning and offline learning. Formative assessment should be carried out in both online and offline learning. Survey findings reveal that students liked blended learning but thought the course was still difficult.
\end{abstract}

Keywords: blended learning, academic writing, teaching reform, formative assessment.

\section{INTRODUCTION}

In 2020, the Foreign Language and Literature Teaching Steering Committee of the Education Ministry issued the new Teaching Guide for Undergraduate English Majors in Colleges and Universities. The new teaching guide is the result of seven-year research by many scholars in the field of foreign language teaching, supported by foreign language teachers all over the country, and provides guidelines for the teaching and cultivation of English majors in China.

The new teaching guide for English majors demands students to master the basic professional theory and research methods. English majors should know the academic standards and how to write academic papers, especially the graduation thesis. However, there are some problems in the traditional teaching of the course-English academic paper writing, which is aimed to cultivate English majors' academic paper writing ability.

This paper is intended to discuss how to reform the teaching of this course based on blended learning, which is significant to improve the teaching quality of this course. This paper will propose a teaching framework for the blended learning of this course, and conclude with some design principles and guidelines for the teaching of the course.

\section{PRESENT PROBLEMS}

According to the survey of the students who learned the course, most students thought the course was very difficult to understand. They needed more time to digest the methodology used in language research, and some of them did not understand the research methods in language study. Some students said they needed more time to understand how to write a literature review and how to use the correct format in an academic paper.

Students also said that the classroom teaching was very limited while the teaching content was so difficult. The teaching time allocated to the course of English academic paper writing was only 16 periods in which students had to learn eight lectures covering how to choose a thesis topic, how to used library databases, how to write a thesis proposal, the research methods, how to write literature review, how to make an outline for the whole thesis, how to argue and prove the viewpoints, how to use the correct format of a thesis, etc. The learning content was too much while the teaching time was too limited. 


\section{BLENDED LEARNING}

\subsection{Personalized Learning and Competency- based Learning}

The development of the application of information technology in the field of education makes blended learning possible nowadays. Blended learning is originated from online learning. The concept of blended learning in educational technology usually refers to a deliberate blending of face-to-face and online instructional activities, with the purpose of stimulating and supporting learning[1].

In the process of blended learning, part of students learning is conducted through online learning during which students can autonomously choose their study time, place, approach or pace[2]. The other part of blended learning is carried out in a classroom supervised by the course teacher.

Blended learning makes personalized learning and competency-based learning possible. Personalized learning is conducted according to students' individual features and helps students to realize their corresponding learning goal. Personalized learning can help students maximize their learning achievements[3]. In competency-based learning, students must master the previous knowledge before they learn next concept. If students do not understand the previous concept before they learn the next one, there will be bugs in their future learning. The learning effect of competency-based learning is better than that of time-based learning[4].

Personalized learning and competency-based learning constitute the system of student-centred learning, of which the key part is students' autonomous learning, sense of belonging in their learning progress, and sustainable leaning ability that helps students become a lifelong learner. How to carry out the largescale personalized learning and competency-based learning is a big challenge for educators.

Blended learning is the engine to accelerate personalized learning and competency-based learning. The information technology in blended learning can customize various learning needs of different students, and online learning that is not limited by time or space makes students learn in various approaches and paces. The face-to-face classroom learning in blended learning is a supplement for online learning. In face-to-face classroom learning, teachers can answer students' questions in their personalized learning. Combining online learning and face-to-face classroom learning paves the way for the popularization of student-centred learning.

\subsection{The Mode of Blended Learning}

Blended learning can take the following forms.

The first form of blended learning is the flipped classroom. In flipped classroom, students learn the new knowledge before they come to the classroom. Students learn the new knowledge by learning the online teaching videos, online teaching materials, like e-books, teachings' lecture notes, online exercises and tests, etc. Students can discuss with their classmates online and search the relevant literature to fully understand the knowledge. If students do not understand the new knowledge when they watch the teaching videos, they can watch them again and again, which is quite different from traditional classroom teaching in which the teachers' teaching is carried out only once. In the flipped classroom, the teacher explains the students' questions and helps the students solve their learning problems in the class, which in traditional teaching the teacher is expected to teach the new knowledge.

The second form of blended learning is the rotation mode. In such rotation mode, there is a fixed online learning period in the whole curriculum. Students are arranged to rotate between the online learning period and classroom teaching period. The rotation can be conducted through station rotation, in which the teacher first teaches students in a face-to-face way for the key knowledge, and then students use a learning software to learn the new knowledge and skill and finally students finish the exercises in the software. Another form of rotation mode is called computer room rotation that is similar to station rotation. In computer room rotation, students shift from the traditional classroom to the computer room to get their online learning when online learning is needed. The computer room rotation mode helped nearly 1 million primary school students from the low-income family improve their academic records in the California in 2006[5]. The third form of rotation mode is the individual rotation, in which students can rotate their learning mode according to the task menu that is designed by an algorithm or the teacher.

\section{TEACHING REFORM BASED ON BLENDED LEARNING}

\subsection{Online Learning Platform}

In higher education institutions, important webbased innovations to strengthen e-learning programs that blend in-class teaching and online teaching within the learning process is referred to as learning management system(LMS), which is used to support the course curriculum with many types of tools, such as discussion boards, forum, chat, online grade posting, online exam, file sharing, management of assignments, syllabi, schedules, announcements and course plans[6]. The LMS is an instrument that offers an e-learning platform that uses internet or other networks as a 
transfer tool to process, put in safekeeping and propagate learning resources and support administration and communication related to learning and teaching. In addition, these tools help students organize their instructing tempo and adapt their learning in line with their personal requirements.

In the teaching of the course English academic paper writing, the LMS online platform --Xuexitong is used to offer students the course teaching videos, relevant ebooks, teaching PowerPoint, course exercises, tests, etc.

The online platform Xuexitong can be used to make the live broadcast teaching for distance teaching. In 2020, many university teachers used the live broadcast teaching to offer students lectures. In the platform Xuexitong, teachers can upload their PowerPoint, carry out the online broadcast teaching, conduct various online teaching activities, such as students' signing in, topic discussion, voting, questionnaire survey, quiz, etc.

Teachers design online learning tasks in Xuexitong, and send every learning task according to the teaching schedule of every chapter. These learning tasks can be video watching, material reading, homework, chapter tests, etc.

There is a learning data module in which teachers can see and download students' various learning data in Xuexitong, such as the test grades, learning time, completeness of every learning task, total credits, and frequency of interaction.

\subsection{Balance between Online and Offline Learning}

In blended learning of the course English academic paper writing, the platform Xuexitong is used as the LMS which offers students a guide to their online learning and offline face-to-face learning. How to make a balance between online learning and offline learning is an issue that is discussed by many educators.

In the reform of this course, 32 learning periods are allocated to offline face-to-face classroom teaching of 8 chapters. According to the teaching syllabus, students should spend at least 32 learning periods in their online learning, since the course is difficult to understand and digest for students. That means for every chapter, teachers teach students in the classroom for 4 periods and students carry out their online learning for at least another 4 periods.

Take one chapter "How to write an abstract" for example, before students come to the classroom for offline learning, students should spend 2 periods in their online learning for previewing. After they take part in the classroom teaching of 3 periods, they should spend one period in their online learning for reviewing and another one period for online exercises. Finally, students come to the classroom for offline learning, in which the teacher answers students' questions and explain the difficult points in students' exercises. The time allocation of each one chapter in online and offline learning is shown in Table 1 .

Table 1. Time Allocation for Each Chapter

\begin{tabular}{|l|l|l|}
\hline Form & Time & Content \\
\hline Online & 2 periods & $\begin{array}{l}\text { Students preview the relevant } \\
\text { concepts and writing skills. }\end{array}$ \\
\hline Offline & 3 periods & $\begin{array}{l}\text { The teacher conducts classroom } \\
\text { teaching of academic writing. }\end{array}$ \\
\hline Online & 1 period & $\begin{array}{l}\text { Students read the relevant material } \\
\text { online to review. }\end{array}$ \\
\hline Online & 1 period & $\begin{array}{l}\text { Students do online exercises for } \\
\text { consolidation of the knowledge. }\end{array}$ \\
\hline
\end{tabular}

\subsection{Assessment of Blended Learning}

It is well documented that effective formative assessment practices are associated with improved student academic achievement, and advances in information technology have enabled the union of blended learning and formative assessment[7]. Students care more about the fairness of assessment and the level of feedback they receive. In the teaching reform of the course--English academic paper writing, the assessments of blended learning based on online learning have the potential to provide an effective mechanism for giving feedback students need in supporting students' learning process.

The formative assessment of blended learning of the course include two parts: the assessment of the online learning and the assessment of the offline classroom learning. The online learning part constitute $40 \%$ of the total final grade, and the offline learning part constitute the other $60 \%$ of the total final grade. The rating of students' online learning is based on students' online learning data, including students' learning time, completeness of every learning task, participation of topic discussion, grades of online exercises and tests, peer review, course credits,etc., which can be downloaded from the online platform --Xuexitong. Students' offline classroom learning is rated according to students' in-class exercises and tests, students' attendance of the class, students' performance in classroom activities, such as answering the teacher's questions, presentations aided by PowerPoint, performance in group research work, etc. Students' grades in online learning and offline learning form their final grade.

\subsection{Students' Learning Experience}

This new teaching model of the course --English academic paper writing based on blended learning was 
carried out in Wuhan Textile University among English majors for a whole term.

After students finished learning the whole course, a survey was conducted among the students. Most of the students, covering $91 \%$ of the all, liked the blended learning mode of the course, while $84 \%$ of the students thought the course was still very difficult. Nearly half of the students, covering $48 \%$ of the all, thought there was too much homework in both online and offline learning, and they spent more time in this course than other courses.

Some students suggested that the teacher should offer some academic papers written by previous students to show them how to improve the papers and some excellent papers to show them how to write a good paper. Some students still suggested that the teacher should offer more help in their online learning, for example offering guidance in their material reading. Some students suggested that the teacher should give them a training on how to operate the online platform, because they sometimes failed to operate it and wasted time on unimportant matters. Still some students suggested that the teacher should make the learning schedule easier for them to follow because they felt stressed when they learned the course.

\section{CONCLUSION}

Blended learning is a good alternative to solve students' learning problem of limited class time with a difficult course. In order to implement student-centered teaching, blended learning can be designed to suit students' need of personalized learning and competency-based learning, in which students can choose their studying time, space, learning pace, etc.

In the reform of the course --English academic paper writing, the online platform Xuexitong is used to offer online learning and assessment. When teachers make the blended teaching design of the course, they should keep a balance between the online learning and offline classroom learning. Every learning task of online learning should be designed according to the teaching content and students' learning need. In the assessment part of the blended learning, formative assessment should be carried out in both online and offline learning. Based on students learning experience survey, most students liked the blended learning mode, but still thought the course was very difficult.

This paper proposes a feasible blended learning mode of the course--English academic paper writing, which provides some suggestions for the improvement of the course teaching. Further studies of this field may be carried out to find out a suitable way to design a better model which harmoniously combines the online learning and offline classroom learning, and also a fair way to make assessment of students' learning.

\section{ACKNOWLEDGMENTS}

This paper was sponsored by the teaching research project of Wuhan Textile University--Course Teaching Reform Research of English Academic Paper Writing for English Majors Based on Blended Learning (Project Number: 2020JY079).

\section{REFERENCES}

[1] R. Boelens, S. Van Laer, B. Wever, \& J. Elen, Blended learning in adult education: Towards a definition of blended learning, Adult Learners Online, 2015, pp. 1-2.

[2] Michael B. Horn, Heather Staker, Blended: Using Disruptive Innovation to Improve Schools, San Francisco: Jossey-Bass, 2015.

[3] Benjamin S. Bloom, "The 2 Sigma Problem: The Search for Methods of Group Instruction as Effective as One-to-One Tutoring," Educational Researcher, vol. 13, No.6(Jun.-Jul.), 1984, pp.416.

DOI:http://www.comp.dit.ie/dgordon/Courses/ILT/ ILT0004/TheTwoSigmaProblem.pdf.

[4] Sal Khan, The One World Schoolhouse: Education Re-imagined, New York: Hachette Book Group, 2012, pp. 40-41.

[5] Heather Staker, Eric Chan of the charter school growth fund, in the report The Rise of $\mathrm{K}-12$ Blended Learning(see n.6), 2011, pp.131-133.

[6] Hossein Moradimokhles \& Gwo-Jen Hwang, The effect of online vs. blended learning in developing English language skills by nursing student: an experimental study, Interactive Learning Environments, 2020, pp. 2-10. DOI: https://doi.org/10.1080/10494820.2020.1739079

[7] Sarah Field \& Lucy Jones, Innovations in assessment: an investigation into the role of blended learning as a support mechanism for assessment, The Law Teacher, December 2010, vol. 44, No.3, pp. 378-390. DOI: https://doi.org/10.1080/03069400.2010.524038 